\title{
PROSPECÇÃO DE URÂNIO NO ESTADO DE GOIÁS*
}

\author{
A. M. DE FIGUEIREDO** e P. M. OESTERLEN**
}

\begin{abstract}
Nuclam started in 1977 a reconnaissance project in central Goiás based on previous work carried out by CNEN and Nuclebrás. The main motivation has been the similarity in regional geology to areas of Canada and North Australia where some years ago important uranium deposits have been found. Systematic prospecting by means of various technics ranging from regional to detailed scale have been carried out from 1978 to 1980 with promising results. In the Northwestern part of the project area a pegmatite type Uranium mineralization has been localized, which is characterized by low grade and small tonnage. More favourable are the mineralizations encountered in the South and West of Campos Belos. They are related to faults and cataclastic schists, formed out of basement rocks by shear tectonics of the Uruaçuan orogenetic cycle (structure controlled mineralization). Another promising mineralization has been encountered recently, further to the West, in migmatitic rocks of the basement. The host rock is characterized mainly by a high amount of albite feldspar and only traces of quartz which points to Na-metasomatic events as source of uranium. The metasomatism apparently started during the Uruaçuan Cycle and has been still active post-tectonically. The lithologically and structurally controlled mineralization is spread out over an area of ca. $6 \times 1,5 \mathrm{~km}$. The field work is still in the preliminary phase, thus final results have not yet been obtained. The finding of the metasomatic mineralization type in Goiás is the first located in central Brazil.
\end{abstract}

INTRODUÇÃo Baseada em trabalhos anteriores da CNEN e da Nuclebrás, a Nuclam iniciou seus trabalhos de prospecção de urânio em 1977 , numa área de aproximadamente $34000 \mathrm{~km}^{2}$, no centro de Goiás (Fig. 1). O projeto, administrado pelo Escritório Regional da $\mathrm{Nu}-$ clam em Brasília, está atualmente na fase de exploração.

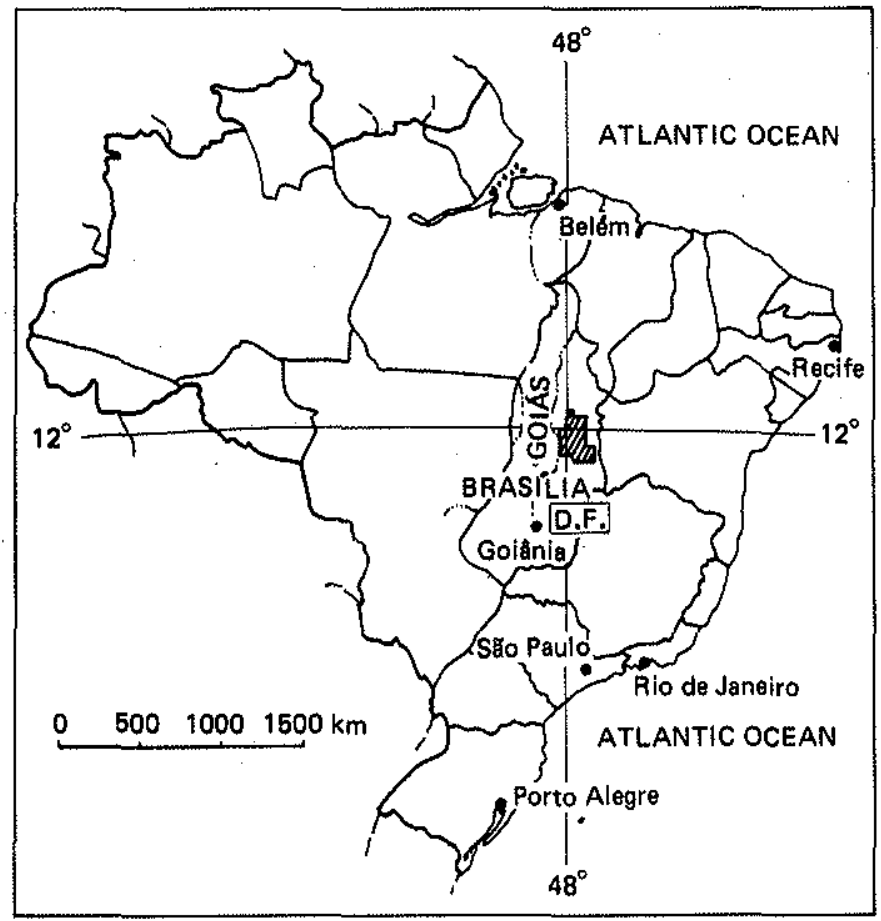

Figura 1 - Localização da área do projeto
Esta área foi inicialmente selecionada devido à analogia com áreas de geologia similar no Canadá, onde depósitos uraníferos com grande tonelagem e alto teor foram descobertos próximos à discordância entre rochas do Proterozóico Inferior e Médio. Esses tipos são chamados "tipo inconformidade" ou do "tipo veio". A premissa era a de que o Grupo Araí representaria uma equivalência ao Grupo Kombolgie (Austrália) e ao Grupo Athabasca (Canadá), ambas discordantes sobre Embasamento Arqueano ou Proterozóico inferior. Esta hipótese encontra apoio no fato de as ocorrências uraníferas em Campos Belos, inicialmente trabalhadas pela Nuclebrás, apresentam características ambientais semelhantes aos depósitos canadenses e australianos.

SITUAÇÃO GEOLÓGICA A área do projeto é constituída principalmente por rochas do Complexo Basal ("Pré-Cambriano Indiviso") representado principalmente por gnaisses e rochas migmatíticas (Tab. 1). Esta sequiencia de rochas, especialmente afetadas pelo ciclo orogenético Transamazônico, é considerada de idade Arqueana - Proterozóico Inferior (mais de 1700 m.a.).

A unidade pré-Cambriana subseqüente, chamada Grupo Araí ou Grupo Natividade, depositada discordantemente sobre o Complexo Basal, é constituída na parte inferior (Formação Arraias) principalmente por rochas quartzíticas metassedimentares e na parte superior (Formação Traíras) por quartzitos e xistos. Este grupo representa o intervalo de tempo no Proterozóico Médio (1700-1100 m.a.).

A mais jovem unidade pré-Cambriana são metapelitos e rochas carbonáticas do Grupo Bambuí de idade Proterozóica Superior.

* Palestra proferida no XXXI Congresso Brasileiro de Geologia, Camboriú, 1980

** Nuclam S.A., Escritório Brasilia, Avenida W-3 Norte, Q. 504, Edifício Marianna, Sobreloja, Salas 4 a 20, CEP 70730 , Brasília, DF 
Tabela I - Estratigrafia, sedimentação, tectônica e metamorfismo da área do projeto (segundo Dardenne, 1978, modificado)

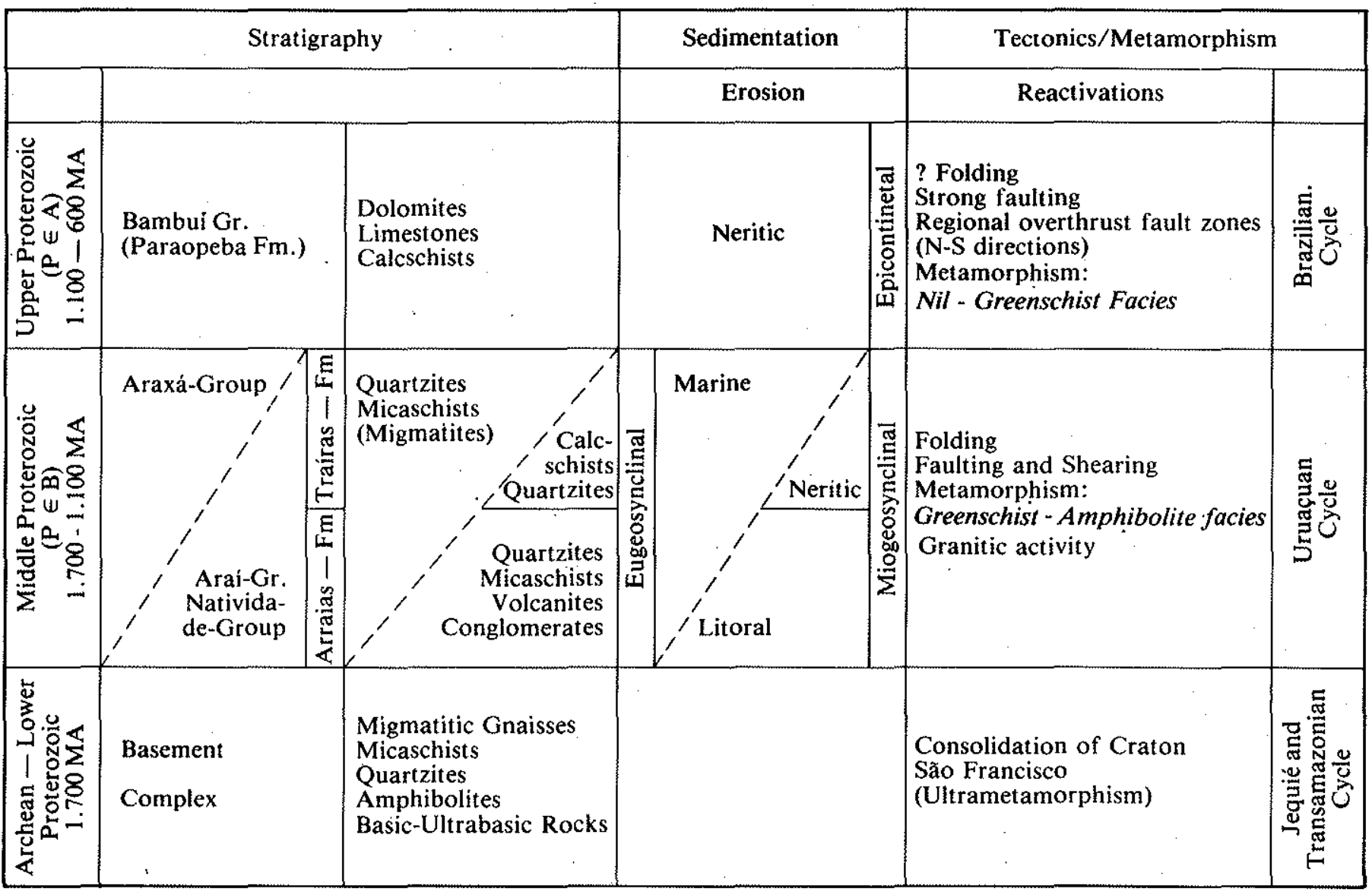

A geologia da área do projeto é complexa devido às várias orogêneses pré-Cambrianas a que foi submetida. Quatro ciclos orogenéticos podem ser destacados; começando com o ciclo Jequié (2500 m.a.), o ciclo Transamazônico (2500-1700 m.a.), o ciclo Uruaçuano (1700-1100 m.a.) e finalizando com o ciclo Brasiliano (1100-600 m.a.). Os eventos magmáticos-orogenéticos mais bem caracterizados na área pertencem ao Uruaçuano, com o aparecimento de granitos intrusivos e efusivas ácidas-básicas, e formação de falhamentos com cisalhamento nas rochas do embasamento e Grupo Araí.

Outro fator que complica mais a situação geológica é a localização da área do projeto com respeito à posição geotectônica entre o Craton São Francisco e a bacia adjacente. Uma parte leste da área é ainda caracterizada por feiçðes cratônicas, enquanto o ambiente geossinclinal já é evidente na parte oeste (Tab. 1, Dardenne, 1978, e outras publicaçðes).

Trabalho realizado de 1977 a 1980 A geologia regional é bem conhecida por meio dos projetos de mapeamento, LETOS da PROSPEC-DNPM-CPRM-(1976), e BRASÍLIA, da PROSPEC-DNPM-(1969). Recentemente, mapeamento mais detalhado foi feito em algumas partes da área de interesse pelo DNPM-CPRM (Projeto NATIVIDADE e Projeto CANABRAVA-PORTO REAL, 1979). Informaçð̌es fundamentais são obtidas dos mapas de gama-espectrometria e magnetometria aérea dos pro- jetos Serra da Mesa (CNEN-CBG, 1973) e Dianópolis (NUCLEBRÁS/LASA, 1975) que cobrem 95\% da área atual do projeto.

A Nuclam iniciou suas atividades na região em 1977 com um projeto de reconhecimento cujo objetivo era verificar em geral as condiçðes geológicas para mineralizaçðes de urânio do tipo "Unconformity". Com o reconhecimento no campo de grupos de anomalias aéreas, encontraram-se situações geológicas similares às do Canadá e da Austrália, e descobriram-se as primeiras anomalias radiométricas. Em 1978, quatro subáreas selecionadas com os critérios acima mencionados foram sistematicamente trabalhadas com geoquímica regional de água e sedimento de corrente, e levantamento semiregional radiométrico, utilizando helicóptero. No final de 1978 , anomalias radiométricas promissoras e as primeiras mineralizaçð̌es de urânio foram delimitadas nas partes norte e sul da área do projeto.

Em 1979, a área do projeto foi aumentada para sul com a inclusão da região de Campos Belos, que fazia parte de um projeto da Nuclebrás, onde, de 1975 a 1978, fundamentais levantamentos de exploração e prospecção foram desenvolvidos. Os trabalhos continuaram com pesquisas detalhadas em áreas favoráveis ao norte e ao sul: mapeamento geológico detalhado de superfície e de trincheiras, além de levantamento detalhado por helicóptero nas proximidades das anomalias mais favoráveis. Por outro lado, a prospecção regional conti- 
nuou nas novas subáreas das partes central e SW da área. Amostragem geoquímica, levantamento radiométrico com carros e reconhecimento de anomalias aéreas no campo (parcialmente apoiado por helicóptero) foram os trabalhos desenvolvidos nessas subáreas.

Em 1980, as atividades foram orientadas principalmente para o levantamento detalhado de anomalias favoráveis nas subáreas Campos Belos e D'Ouro (Fig. 2). Além do mapeamento detalhado de superfície e das trincheiras, realizaram-se amostragens detalhadas de solos e várias técnicas de geofísica, tais como magnetometria, VLF e eletrorresistividade (Tab. 2 e Fig. 2).

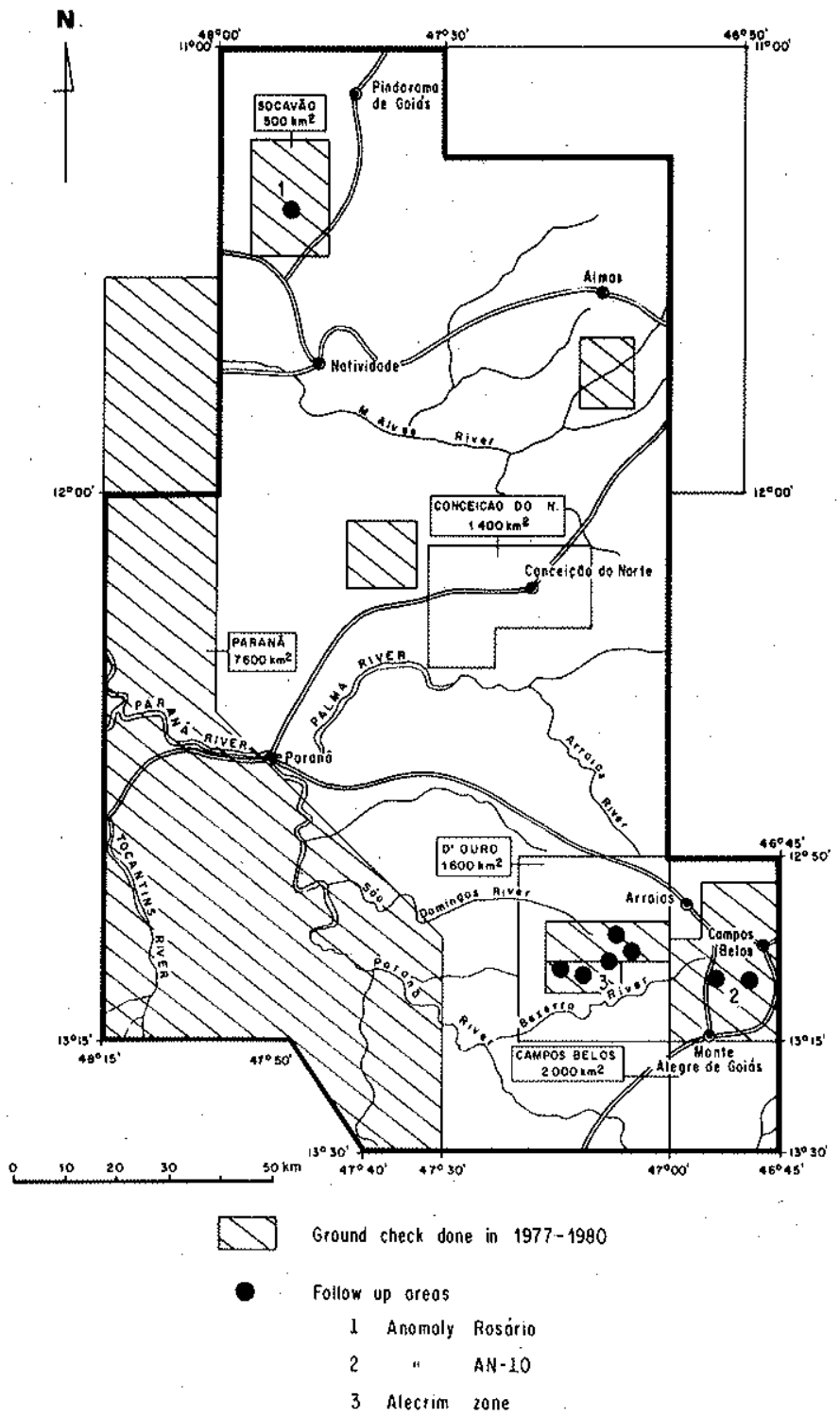

Figura 2 - Localização das subareas e trabalho realizado, $1977-1980$

RESULTADOS Como resultados das atividades acima descritas, centenas de anomalias de urânto foram localizadas e pesquisadas, e muitos dados referentes à geologia da área do projeto foram obtidos. Os trabalhos se concentraram nas anomalias mais interessantes, tendo em vista o significado econômico e o aspecto genético mais
Tabela 2 - Trabalhos realizados e métodos aplicados no projeto, $1977-1980$

\begin{tabular}{|c|l|l|}
\hline Ano & Tipo de trabaiho & \multicolumn{1}{|c|}{ Métodos Aplicados } \\
\hline 1977 & Reconhecimento & $\begin{array}{l}\text { Estudo da geologia regional } \\
\text { Reconhecimento de anomalias } \\
\text { aéreas radiométricas }\end{array}$ \\
\hline 1978 & Prospecção & $\begin{array}{l}\text { Levantamento radiométrico por } \\
\text { helicóptero } \\
\text { Geoquímica regional de água } \\
\text { Geoquímica regional de sedimento } \\
\text { de corrente } \\
\text { Reconhecimento geológico-radio- } \\
\text { métrico de anomalias }\end{array}$ \\
\hline 1980 & $\begin{array}{l}\text { Prospecção } \\
\text { Prospecção e }\end{array}$ & $\begin{array}{l}\text { Geoquímica regional de água } \\
\text { Geoquímica regional de sedimento } \\
\text { de corrente } \\
\text { Levantamento radiométrico com } \\
\text { veículos } \\
\text { Reconhecimento geológico-ra- } \\
\text { diométrico de anomalias } \\
\text { Detalhamento geológico-radiométri- } \\
\text { co (mapeamento e amostragem de } \\
\text { trincheiras) } \\
\text { Levantamento radiométrico semi- } \\
\text { detalhado por helicóptero }\end{array}$ \\
$\begin{array}{l}\text { Mapeamento geológico regional } \\
\text { Reconhecimento geológico-ra- } \\
\text { diométrico de anomalias } \\
\text { Detalhamento geológico-radiométri- } \\
\text { co (mapeamento e amostragem de } \\
\text { trincheiras) } \\
\text { Geoquímica de solos, semidetalhe } \\
\text { Geoquímica de solos profunda, } \\
\text { semidetalhe } \\
\text { Geofísica de detalhe (magnetome- } \\
\text { tria, eletrorresistividade e VLF) }\end{array}$ \\
\hline
\end{tabular}

favorável para a descoberta de jazimentos. Partindo deste princípio, três das mais interessantes ocorrências de urânio, cada uma delas com características geológicas distintas, serão neste trabalho descritas com mais detalhe.

\section{Mineralização em pegmatitos da Zona Rosário}

A ocorrência, parte da subárea Socavão, situa-se a $40 \mathrm{~km}$ norte da cidade de Natividade (Fig. 2) e com cerca de $750 \times 450 \mathrm{~m}$. As mineralizações de urânio e tório estão associadas a pegmatitos quartzo-feldspáticos pré-Cambrianos e rochas anfibolíticas, que são as encaixantes. A fonte de urânio e tório foram os pegmatitos. $O$ urânio aparentemente migrou para as rochas anfibolíticas da zona de contato e o tório permaneceu dentro dos pegmatitos (Fig. 3). O fenômeno de enriquecimento de urânio no contato de rochas anfibolíticas é citado em outras ocorrências no mundo.

O potencial de urânio desta ocorrência é considerado muito limitado, sendo os teores baixos (250 ppm $\mathrm{U}_{3} \mathrm{O}_{8}$ ). A zona mineralizada raramente excede a espessura de $10 \mathrm{~m}$ e os pegmatitos possuem pequenas dimensð̃es em superfície, motivando o abandono da área após uma prospecção detalhada. 


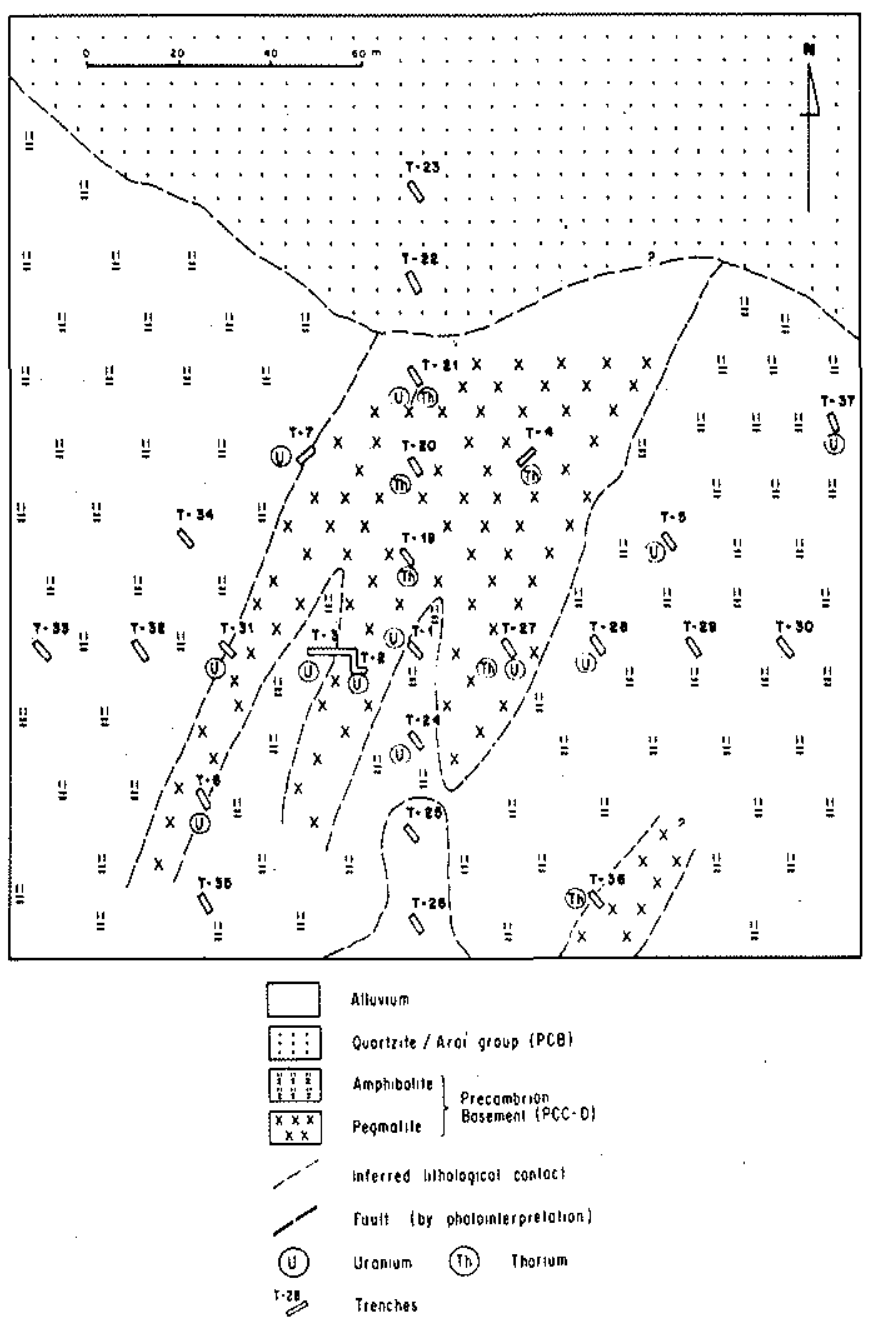

Figura 3 - Mapa geologico da zona central, anomalia Rosário

Mineralizações controladas por estruturas tectônicas de Campos Belos Mais importantes são as ocorrências uraniferas situadas ao sul e a oeste da cidade de Campos Belos (Figs. 2 e 4). Como resultado do reconhecimento geológico-radiométrico, mais de 100 anomalias de urânio foram catalogadas sendo selecionadas dez ocorrências de maior significado, principalmente as mineralizações das anomalias AN-2 e AN-10 (Fig. 4). Como se observa nas Figs. 4 e 5 , todas as zonas mineralizadas estão associadas a estruturas tectônicas, sendo $0^{\circ}, 50^{\circ}$ e $140^{\circ}$ as direçðes estruturais mais características. O urânio está associado geralmente a quartzo sericita xisto com grafita, e as rochas granitóides e granito gnaisses, pertencentes ao complexo basal.

Os xistos com grafita foram formados devido a processos de cisalhamento nas rochas do embasamento, sendo comuns na região típicas feições de deformações tectônicas, tais como milonitos, brechas, estruturas do tipo augen, além de transiçőes entre as rochas originais e os produtos tectonizados. Investigações petrográficas e analíticas confirmaram a semelhança da composição mineral das rochas do complexo Basal com os xistos miloníticos. De um modo geral, a seqüência de rochas está
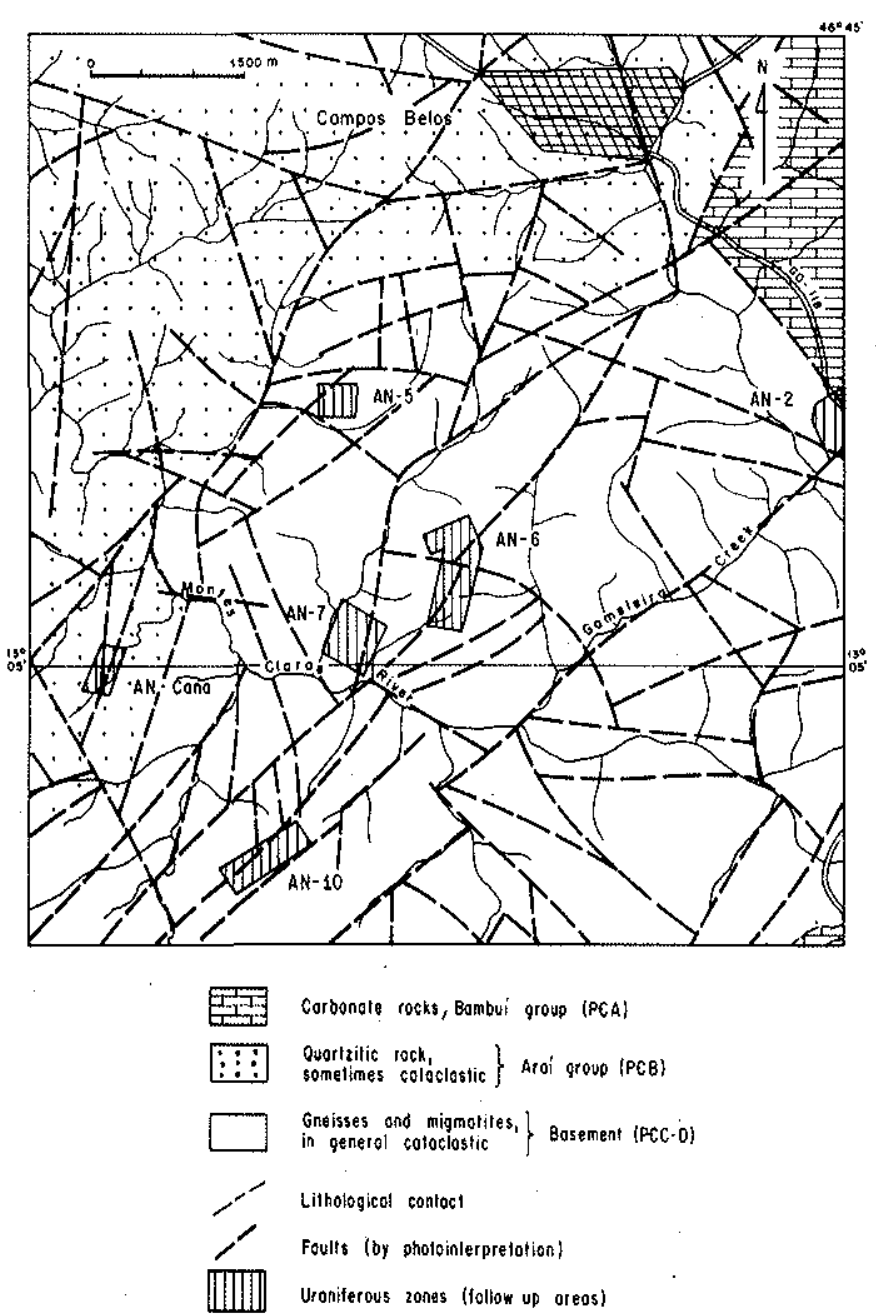

Figura 4 - Mapa geológico da parte sul de Campos Belos com zonas de mineralização

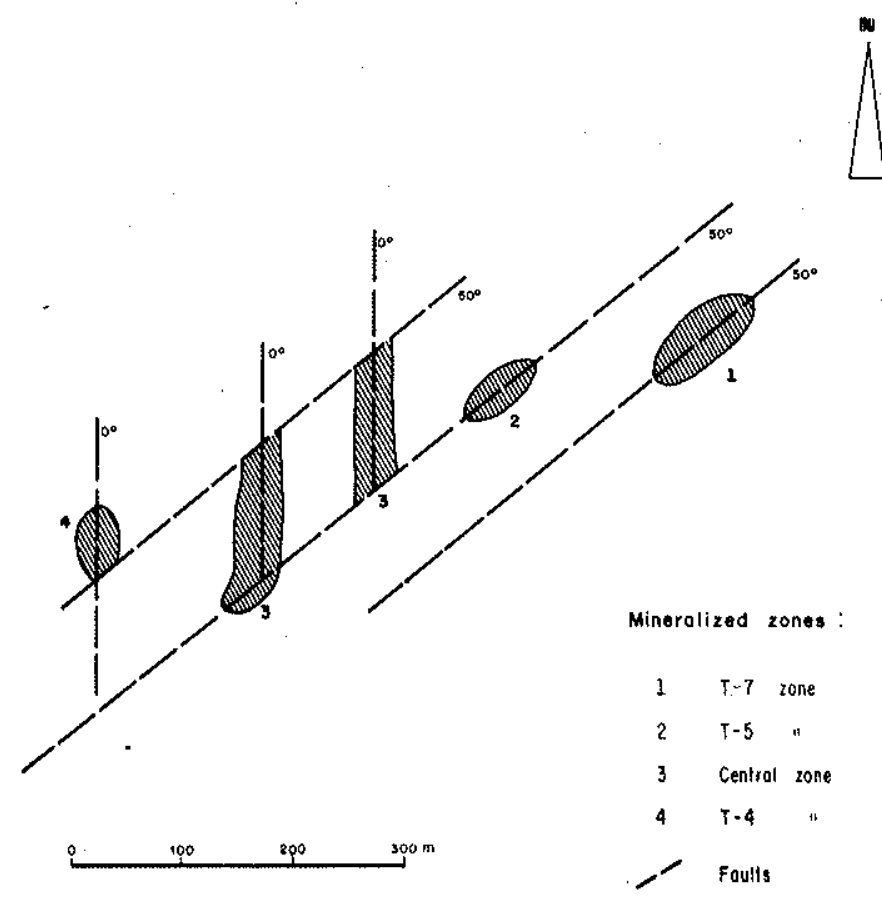

Figura 5 - Relação das mineralizações com as estruturas tectônicas, anomalia $A N-10$ 
intensamente foliada devido ao cisalhamento e num estágio avançado de alteração (sericitização, milonitização, caulinização).

A mineralização é constituída só por minerais de urânio de origem secundária, principalmente autunita (fosfato de urânio e cálcio), torbernita (fosfato de urânio e cobre) e renardita (fosfato de urânio e chumbo). Maiores indicações para uma natureza epigenética são dadas pelo caráter descontínuo das mineralizaçðes em superfície. $\mathrm{O}$ teor de urânio varia consideravelmente de 100 ppm de $\mathrm{U}_{3} \mathrm{O}_{8}$ em $0,5 \mathrm{~m}$ a $0,5 \%$ em $10 \mathrm{~m}$. Neste tipo de ocorrência, a zona de mineralização com altos teores possui, geralmente, espessura e extensão limitada, porém nas vizinhanças ocorre um halo de dispersão de maiores dimensðes com teores de 50-200 ppm de $\mathrm{U}_{3} \mathrm{O}_{8}$.

$\mathrm{O}$ tipo de ocorrência de urânio controlado por estruturas tectônicas é amplamente encontrado na parte sul da área do projeto, sendo que as ocorrências com melhor potencialidade estão situadas nas vizinhanças da cidade de Campos Belos, onde os trabalhos de prospecção da Nuclam se encontram em fase complementar, a fim de selecionar as zonas mineralizadas mais promissoras para um programa de sondagem.

Essas mineralizaçðes de Campos Belos mostram algumas feiçסes típicas dos depósitos uraníferos, do tipo inconformidade, encontrados no Canadá e na Austrália. A melhor evidência é marcada pela proximidade da zona uranífera com o contato do Complexo Basal com o Grupo Arai, isto é, Arqueano-Proterozóico Inferior/Proterozóico Médio. Outro ponto de semelhança é a forte alteração da rocha hospedeira devido ao metamorfismo retrógrado regional do final do ciclo Uruaçuano. Por outro lado, algumas indicaçoes geológicas são favoráveis para o modelo de mineralização de urânio associado a uma fonte granítica. Isto é fundamentado principalmente pelas relaçðes do urânio com rochas granitóides-pegmatíticas nas anomalias e na presença de granitos, graissens e pegmatitos da província estanífera-tantalífera situada próximo e ao sul de Campos Belos. Neste caso, as mineralizações poderiam ser oriundas de mobilizaçð̃es tardias uraníferas das intrusões graníticas, e o evento termal seria considerado como parte final do ciclo Uruaçuano, de acordo com as idades de datação de granitos da área $(\mathrm{Ha}-$ sui et al., 1980).

Mineralizações do tipo metassomático Um outro tipo de mineralização com boas perspectivas foi localizado recentemente a $40 \mathrm{~km}$ oeste da cidade de Campos Belos em uma área com dimensðes de $6 \times 1,5 \mathrm{~km}$ (anomalia Alecrim-Paiol, Fig. 6). A mineralização está associada a migmatitos do embasamento que foram afetados por processos metassomáticos. O metassomatismo foi caracterizado principalmente pela introdução de soluçoes ricas em sódio e urânio, com modificaçð̌es do quartzo e feldspato potássico. A albita é o mineral principal, contribuindo com até mais de $80 \%$ (albititos). Outra característica das rochas metassomatizadas é a forte alteração possivelmente oriunda de influências hidrotermais, além de intemperismo. Esses processos metassomáticos aconteceram em várias pulsaçðes, o primeiro foi síncrono com o ciclo Uruaçuano e os posteriores foram pós-tectônicos.

A mineralização é de urânio aparentemente de baixo teor, não possuindo tório. Qs minerais de urânio são
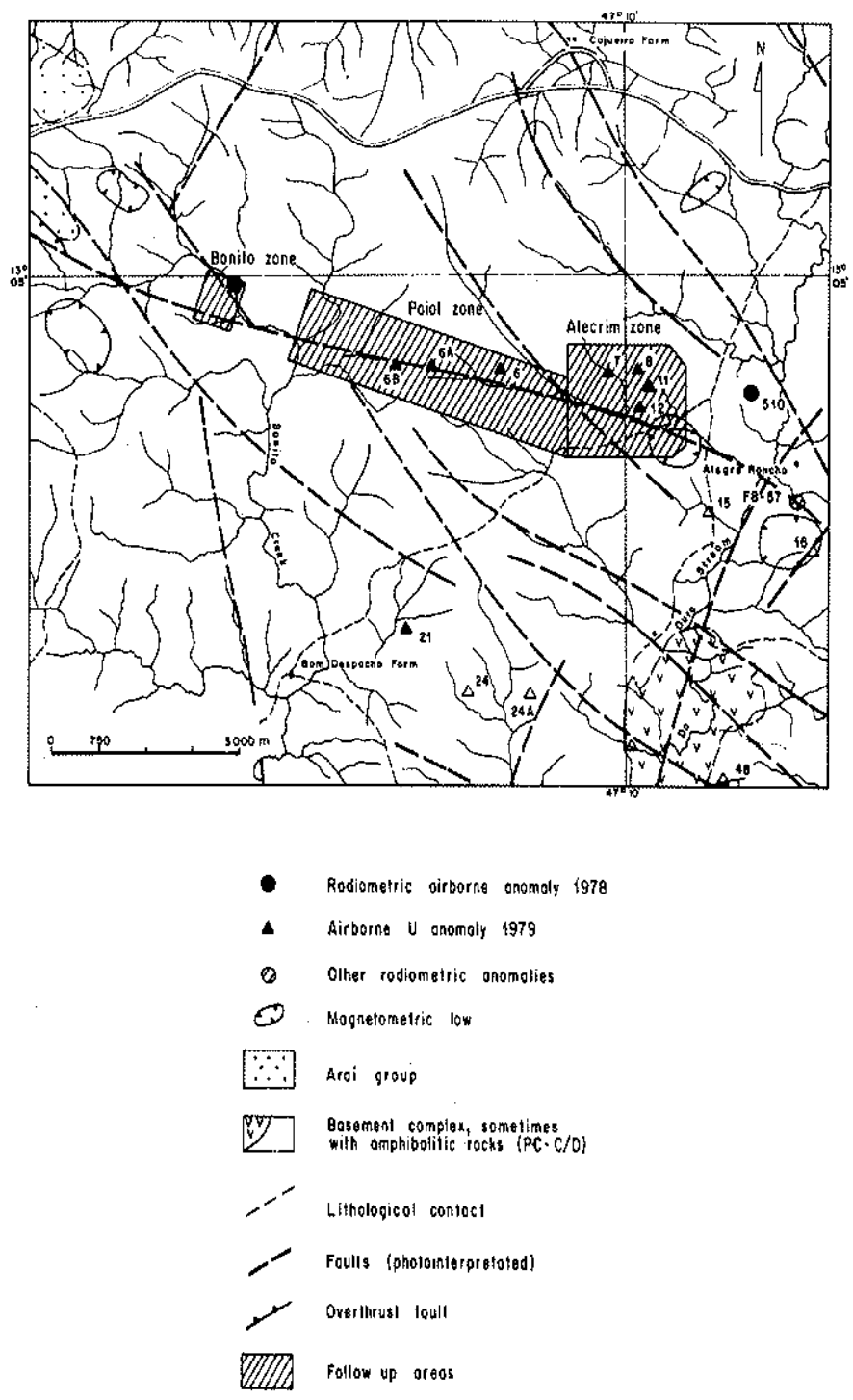

Figura 6 - Zonas anômalas Alecrim, Paiol e Bonito

brannerita (U-Ti-óxido), uraninita, pechblenda e minerais secundários autunita e torbernita. Estudos ao microscópio revelaram que os minerais de urânio estão disseminados nos metassomatitos existindo também concentrações secundárias ao longo das fraturas.

Esta ocorrência de urânio em rochas metassomatizadas é a primeira a ser reconhecida no Brasil central. Os trabalhos de campo estão em andamento e os resultados até agora são bastante animadores, influenciados também pelo fato de que há alguns anos a Nuclebrás bem como a Nuclam já haviam localizado ocorrências similares no nordeste do Brasil e no Estado da Bahia, e que atualmente se encontram em fase final de exploração.

Agradecimentos Os autores desejam agradecer à $\mathrm{Di}$ retoria da Nuclam S.A. por ter permitido a publicação deste artigo. Reconhecem também os esforços e a colaboração prestados pela equipe de geólogos e prospectores do Escritório Regional de Brasília que participaram do planejamento e da execução do projeto. 


\section{BIBLIOGRAFIA}

ARAÚJO, V.A. e CAVALCANTE Alves, A. - 1979 - Projeto CanabravaPorto Real, Relatório final, volume I, texto e ilustraçðes. MME-DNPM, DNPM/CPRM, CPRM, Sup. Reg. Goiânia: $191 \mathrm{pp}$.

BARBOSA, O. et al. - 1969 - Projeto Brásília-Goiás, Relatório Final DNPM/PROSPEC, $225 \mathrm{pp}$.

CORREIA FILHO, F.C.L. e MARTINS DE SÁ, A. - 1980 - Projeto Natividade, Relatório final, volume 1 , texto, ilustraçðes e anexos. MME/DNPM, DNPM/CPRM, CPRM. Sup. Reg. Goiânia; 225 pp.

DAHLKAMP, F.J. - 1980 - Typology and geographic/geotectonic distribution of uranium deposits. Revue l'Instit. Franc. Petrole, XXXV (3), 499-536.

DARDENNE, M.A. - 1978 - Zonação tectónica da borda ocidental do Craton Săo Francisco. Anais do XXX Congr. Bras. de Geologia, Recife, 1: 299-308.

EUPENE, G.S. - 1980 - Stratigraphic, structural and temporal control of mineralization in the Alligator Rivers Uranium province, Northern Territory, Australia. Proceed 5 th Quadrennial IAGOD Sympos., E. Schweizerbart'sche Verlagsbuchhdlg, Germany: 347-376.

GEISEL SOBRINHO, E. et al. - 1980 - O distrito uranifero de Lagoa Real, Bahia. An. XXXI Congr. Bras. Geol., Camboriú, vol. 3, 1499-1512.
HASUI, Y. et al. - 1980 - Dataçóes Rb-Sr e KuAr do centro-norte do Brasil e seu significado geológico-geotectônico. An. XXXI Congr. Bras, de Geol. Camboriú, vol. 5, 2659-2676.

HIGGINS, M.W. - 1971 - Cataclastic rocks, Geol. Survey Prof, Pap. 687, Washington, $97 \mathrm{pp}$.

MARINI, O.J. et al. - 1977 - Contribuição à geologia do Precambriano da porção central de Goiás. Rev. Bras. Geoc. 7 (4): 304-324.

McMILAN, R.H. - 1978 - Genetic aspects and classification of important Canadian Uranium deposits. Mineralog. Assoc. Canada, Short Course Hand book, 3, (ed. M.M. Kimberley): 187.204.

MME/DNPM - 1976 - Carta Geologica do Brasil ao Milionésimo, Folha Brasília SD-23, texto explicativo. Brasilia, $163 \mathrm{pp}$

MOUTINHO DA COSTA, L.A. et al. - 1976 - Projeto Leste do Tocan tins/Oeste do Rio São Francisco. Relatório final, volume Ia. MME/DNPM DNPM/CPRM, PROSPEC: $300 \mathrm{pp}$.

Recebido em 24 de setembro de 1981. 